BMJ Open

Sport \&

Exercise

Medicine

\title{
A comparative analysis of Donald Bradman and Steven Smith: what are their secrets?
}

\author{
Habib Noorbhai
}

To cite: Noorbhai H. A comparative analysis of Donald Bradman and Steven Smith: what are their secrets? BMJ Open Sport \& Exercise Medicine 2020;6:e000720. doi:10.1136/ bmjsem-2019-000720

\section{Check for updates}

(c) Author(s) (or their employer(s)) 2020. Re-use permitted under CC BY-NC. No commercial re-use. See rights and permissions. Published by BMJ.

Sport and Movement Studies, University of Johannesburg, Johannesburg, Gauteng, South Africa

Correspondence to Dr Habib Noorbhai; habibn@uj.ac.za

\section{ABSTRACT}

There has been growing evidence on the batting backlift technique in cricket at varying levels of cricket ability and the way in which batsmen direct or manoeuvre their bat in various ways. Most recently, there has been elevated awareness and discussion around the technique of Steven Smith. To an extent, there has been some comparison and reference been made to Sir Donald Bradman. Both Donald Bradman and Steven Smith have exhibited techniques and movements at the crease which many regard as 'unorthodox' or 'unnatural'. This paper compares each of the batting technique components of both batsmen. The paper describes that both Bradman and Smith held their bat with an open grip which allowed them to hit the ball in most scoring areas of the field. The most common element that both batsmen demonstrate is a backlift that is directed towards the gulley or point region, otherwise known as the rotary method of batting, which is contrary to most of the coaching literature. Future research would require objective measures on Steven Smith to fully understand the kinetics and kinematics associated with his batting technique. The variances of performance averages across other formats (one-day internationals and 20-20 cricket) must be noted.

\section{INTRODUCTION}

The batting technique in cricket consists of various components such as the stance, grip, backlift, downswing, impact with the ball and follow-through. ${ }^{1}$ It has become a wellestablished fact that most successful batsmen do not portray batting techniques or bat the way a majority of coaching manuals have prescribed. ${ }^{2}$ Particularly, in recent years, there has been growing evidence on the batting backlift technique in cricket at varying levels of cricket ability and the way in which batsmen direct or manoeuvre their bat in various ways. ${ }^{3-6}$ Most recently, there has been elevated awareness and discussion around the techniques of batsmen, more specifically Steven Smith, during the 2019 Ashes Test series between England and Australia. To an extent, there has been some comparison and reference been made to Sir Donald Bradman who was the first purist of the "rotary method of batting', more commonly known as the lateral batting backlift technique (LBBT).

Bradman's opinion in a video interview suggested that, "playing with a straight bat was great for defence but not for offence, and that a straight backlift will let you down under pressure'. ${ }^{3}$ An interpretation of a video first produced in 1934 by Bradman explained that the straight backlift encourages players to play forward and to use heavier bats to generate power. ${ }^{7-9}$ This would reduce their ability to play a range of shots with a cross-bat or off the back foot. As a result, they would have a more restricted range of scoring strokes and would be unable to score as rapidly as Bradman did. ${ }^{10}$ If Bradman is correct, then fast-scoring batsmen in the modern game must have adopted some elements of his looped action, as in the case of Steven Smith, who is the closest batsman in the modern era to achieve similar success to Donald Bradman. ${ }^{3}$ This paper aims to provide a descriptive, comparative analysis and viewpoint between these batsmen.

\section{PERFORMANCES IN TEST CRICKET}

Donald Bradman has been regarded as the best batsman of all time with the highest test average of 99.94. Most batsmen have not come close to this prolific statistic except for Graeme Pollock (who achieved an average of 60.97 which was 38.97 shorter). ${ }^{7}$ In modern cricket, there may be one batsman who could be nearing Bradman's test average in the years to come. Steven Smith currently averages 62.84 (as of 25 January 2020) and has scored 2615 runs in the last 26 Ashes tests at an average of 65.37 . $^{11}$

\section{BATTING TECHNIQUE COMPONENTS}

Most coaches emphasise the importance of the grip, stance and backlift as being the foundations for successful batting. ${ }^{12}$ Both Donald Bradman and Steven Smith have exhibited techniques and movements at the crease which many regard as 'unorthodox' or 


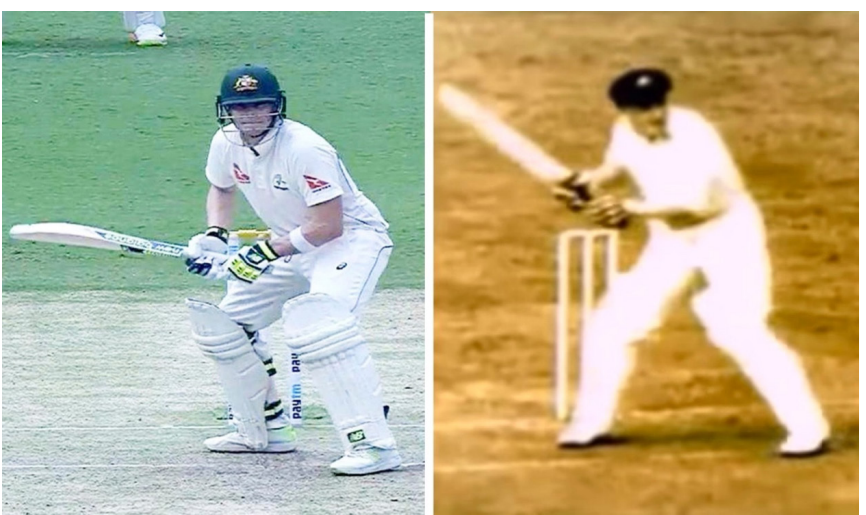

Figure 1 The stance and techniques of Steven Smith (left) and Donald Bradman (right). Note: The picture of Donald Bradman is from an oblique view as no still photos or videos taken from the frontal plane or behind the bowler were captured at the time. Adapted from The Times (https://bit. ly/363Nd6c).

'unnatural'. This section will compare some of the batting technique components (grip, stance and backlift) of both batsmen (figure 1). It must be noted that Steven Smith displays unique habits in each of the batting elements (unlike Bradman), that is, changing numerous pairs of glove in one innings, checking his pads and box guard is in place before each delivery is bowled, and looking to the field placements more than once in an over.

\section{Grip}

Traditional coaching emphasises that the standard grip is one where the bat handle is held with the hands together, with the firmer top hand about $25 \mathrm{~mm}$ from the top of the handle. The hands are positioned so that the 'vees' formed by the thumb and forefinger of each hand are in line with each other, pointing between the splice and the outside edge of the bat. ${ }^{12}$ Bradman adopted a grip that was not consistent with the coaching literature, having the 'vee' of his left hand in line with the splice of the bat. ${ }^{12}$ Both Bradman and Smith held their bat with an open grip which allowed them to hit the ball in most scoring areas of the field. ${ }^{8}$ Their hands lie comfortably around the bat, positioned and rested between their legs as the bowler is running up to bowl. ${ }^{13}$

\section{Stance}

Coaching literature suggested that during the stance, the bat should be placed just behind the back foot. ${ }^{12}$ In the case of Bradman and Smith, during their stance, their bats are rested behind their feet, in which the posterior aspect of the bat faces obliquely towards second slip. The most distinctive feature in the batting technique between the two batsmen is that Smith has a more exaggerated movement across the crease (more than a trigger movement) in which he covers his stumps prior to hitting the ball. Bradman had a similar shuffle across the crease which was less exaggerated than Smith, and did not cover his stumps prior to ball impact.

\section{Backlift}

Most of the coaching literature suggests that the conventional (straight) backlift should enable the bat to be taken back in a line from wicket to wicket with the top hand taking control. The front arm should be extended backwards to provide a wide sweep with minimum flex of the elbow. ${ }^{14}$ The most common element that both batsmen demonstrate is a backlift that is directed towards the gulley or point region, otherwise known as the rotary method of batting. ${ }^{13}$ Another key observation is that both batsmen have an open face of the bat prior to ball impact. If $77 \%$ of the greatest test batsmen of all time, ${ }^{3}$ and if Bradman and Smith (who have the two highest test averages) have adopted the LBBT, how is it not regarded as orthodox? The key question here is: why don't we teach the LBBT to young cricketers? One study revealed that most coaches found it challenging to teach and would require some level of experience for teaching a backlift that is not advocated in the coaching literature. ${ }^{15}$

\section{Downswing}

The key aspect is that despite their bats being directed away from their body (with their hands close to their hips), they are still able to bring the bat straight down. This is for both front-foot or back-foot shots. A study ${ }^{16}$ showed that using a bowling machine results in batsmen adopting different timing and coordination patterns for balls bowled by an actual bowler of similar speed. Against a bowling machine projecting cricket balls at $26.76 \mathrm{~m} / \mathrm{s}$, batsmen attempted to couple the backswing to the moment the ball was released $(0.02 \pm 0.10 \mathrm{~s})$, whereas, against the real bowler, the backlift started later $(0.12 \pm 0.04 \mathrm{~s})$. Even though the timing of the backlift initiation was different, results from other research suggests that the batsmen may have attempted to standardise the initiation of the downswing effectively to control the temporal duration of this phase of the technique. Furthermore, it was also found that the downswing commenced earlier when facing the bowling machine $(0.32 \pm 0.04 \mathrm{~s})$ compared with the bowler $(0.41 \pm 0.03 \mathrm{~s})$ showing that bat speed differed in the two conditions. ${ }^{17}$

These results suggest that coaches should think very carefully before using bowling machines in practice with expert players who gain a perceptual advantage from being able to use important information from bowling actions. ${ }^{12}$ With Bradman and Smith in particular, it remains plausible whether bowling machines were used during their practice situations. Donald Bradman and Steven Smith portray a technique that allowed them to reduce successive failures and margin for errors, which enabled them to have a highly effective ability to anticipate bowling actions from an array of bowlers. This anticipation is integral as it influences their downsing of the bat prior to impact with the ball.

\section{RECOMMENDATIONS}

Coaches, scientists and analysts have learnt too often not to 'pigeon-hole' cricketers, especially how they appear 
technically. ${ }^{18}$ The same concern was put forward on the longevity of players' careers (if they had an 'unorthodox' technique) with Hashim Amla, Steven Smith, among others, yet these batsmen still display attributes of success. One could argue that individual variation for all batsmen is key. But for batsmen such as Donald Bradman and Steven Smith, their backlift (or rotary method) appears to be their key determinant for success. Future research would require objective measures on Steven Smith to fully understand the kinetics and kinematics associated with his batting technique. The variances of performance averages across other formats (one-day internationals and 20-20 cricket) must also be noted. Furthermore, other factors that may affect performance, such as the weight of the bat, type of bowlers, pace of the bowler and speed of the bat, should also be considered.

Twitter Habib Noorbhai @Habib_Noorbhai

Acknowledgements The authors thank The Times for the image used in figure 1. Contributors HN conceptualised and wrote the paper.

Funding The authors have not declared a specific grant for this research from any funding agency in the public, commercial or not-for-profit sectors.

Competing interests None declared.

Patient consent for publication Not required.

Provenance and peer review Not commissioned; externally peer reviewed.

Open access This is an open access article distributed in accordance with the Creative Commons Attribution Non Commercial (CC BY-NC 4.0) license, which permits others to distribute, remix, adapt, build upon this work noncommercially, and license their derivative works on different terms, provided the original work is properly cited, appropriate credit is given, any changes made indicated, and the use is non-commercial. See: http://creativecommons.org/ licenses/by-nc/4.0/.

ORCID iD

Habib Noorbhai http://orcid.org/0000-0001-9464-6854

\section{REFERENCES}

1 Stretch RA, Bartlett R, Davids K. A review of batting in men's cricket. J Sports Sci 2000;18:931-49.

2 Sarpeshkar V, Mann DL. Biomechanics and visual-motor control: how it has, is, and will be used to reveal the secrets of hitting a cricket ball. Sports Biomech 2011;10:306-23.

3 Noorbhai MH, Noakes TD. A descriptive analysis of batting backlift techniques in cricket: does the practice of elite cricketers follow the theory? J Sports Sci 2016;34:1930-40.

4 Noorbhai MH, Noakes TD. An analysis of batting backlift techniques among coached and un-coached cricket batsmen. S Afr J Res in Sport Phys Educ Recreat 2016;38:143-61.

5 Noorbhai M, Noakes T. The lateral batting backlift technique: is it a contributing factor to success for professional cricket players at the highest level? S Afr J Sports Med 2019;31:1-9.

6 Noorbhai H, Noakes TD. The lateral batting backlift technique in cricket: does it affect other components of the batting technique? Afr J Phys Act Health Sciences 2019;25:184-99.

7 Borooah VK, Mangan JE. The "Bradman Class": An exploration of some issues in the evaluation of batsmen for test matches. 18772006. Berkeley Electronic Press: Berkley, 2010.

8 Bradman D. The art of cricket. London: Robson Books Ltd, Hodder \& Stoughton, 1958.

9 Shillinglaw T. Bradman revisited 2nd edition 'The Simplicity of Nature'. United Kingdom, 2009.

10 MacLaren AC. The perfect batsman: JB Hobbs in action. London: Cassell and Company, Ltd, 1926.

11 ESPN Cric Info. Graeme pollock. Available: http://www.espncricinfo. com/southafrica/content/player/46772.html [Accessed 5 Aug 2019].

12 Glazier P, Davids K, Renshaw I, et al. Uncovering the secrets of the Don: Bradman reassessed. Sport Health 2005;22:16.

13 Shillinglaw T, Hale B. The Bradman Phenomenon. Continuous 'Rotary' Batting Process. LDCC: Lancashire, 2008.

14 Andrew K. The skills of cricket. Marlborough. The Crowood Press 1992.

15 Noorbhai MH, Noakes TD. An evaluation of the coaching methods of the batting backlift technique in cricket. J Qual Res Sports Studie 2018;12:35-56.

16 Pinder RA, Renshaw I, Davids K. Information-movement coupling in developing cricketers under changing ecological practice constraints. Hum Mov Sci 2009;28:468-79.

17 Renshaw I, Oldham ARH, Davids K, et al. Changing ecological constraints of practice alters coordination of dynamic interceptive actions. Eur J Sport Sci 2007;7:157-67.

18 Noorbhai $\mathrm{H}$, Noakes $\mathrm{T}$. Coaching implications of the lateral batting backlift technique in men's cricket: a discussion and food for thought. BMJ Open Sport Exerc Med 2019;5:e000494. 